\title{
Extracellular field signatures of CA1 spiking cell assemblies during sharp wave-ripple complexes
}

\author{
Jiannis Taxidis ${ }^{1 *}$, Kamran Diba $^{2}$, Costas A Anastassiou ${ }^{1}$, György Buzsáki ${ }^{3}$, Christof Koch ${ }^{1}$ \\ From Twenty Second Annual Computational Neuroscience Meeting: CNS*2013 \\ Paris, France. 13-18 July 2013
}

\begin{abstract}
Although postsynaptic and transmembrane currents over local neuronal populations are considered the main factors for shaping local field potential (LFP) and current source density (CSD) fluctuations [1], high-frequency oscillatory LFPs can also be shaped by extracellular action potentials of pyramidal cell populations [2]. Sharp wave-ripple complexes (SWRs) are typical examples of such high-frequency oscillatory events, observed in hippocampal LFPs during deep sleep and awake immobility. They consist of an extensive depolarization in the CA1 dendritic layer (sharp wave) arising from population bursts in CA3, accompanied by a 150-200 Hz LFP oscillation in the CA1 pyramidal layer (ripple). During SWRs, temporal firing patterns of correlated place cells, acquired during wakeful exploration, are replayed in fastscale, providing a strong indication for the participation of SWRs in memory consolidation. Yet the particular effects of these pattern replays on the hippocampal extracellular field are largely unknown. How are the different ensembles of spiking cells encoded in the emerging ripple-LFPs? Here, we study this association through both a modeling and an experimental approach.
\end{abstract}

Firstly, we employ a spiking network model of the CA3 and CA1 hippocampal areas that reproduces key features of SWRs based on synchronous CA3 population bursts and strong, fast-decaying CA1 recurrent inhibition [3]. The synaptic input on CA1 pyramidal cells is implemented in a population of morphologically realistic, multi-compartmental models of CA1 pyramidal neurons, based on reconstructed cells [4]. The emerging extracellular fields accurately reproduce properties of SWR LFPs. By developing different spatial distributions of sets of CA1 cells that fire during ripples and others that remain silent, we

\footnotetext{
* Correspondence: jtaxidis@caltech.edu

'Computation and Neural Systems, California Institute of Technology, Pasadena, CA 91125, USA

Full list of author information is available at the end of the article
}

explore in a systematic fashion the influence of spiking cell assemblies on the spatiotemporal characteristics of emerging extracellular fields during SWRs. In particular, we show how the different spatial arrangements of spiking cells give rise to differences in the depth-profile and CSD characteristics of raw and filtered LFPs.

Next, we apply our analysis to a set of LFPs and unit activity, recorded in vivo, from multiple locations in areas CA 3 and CA 1 of the rat hippocampus while animals run on a linear track with resting areas at both ends. The spiking activity of detected place cells, firing in sequence during the running sessions, is replayed in either forward or reverse order during SWRs occurring at the resting areas [5]. We trace the differences in the depth profile and CSDs of SWR LFPs between such forward and reverse replays. Based on our modeling results, we provide a link between systematic changes in the spatiotemporal features of the LFPs, with the corresponding ensembles that gave rise to each ripple episode.

This work provides a deeper understanding of the nature of extracellular fields and offers a new approach to the decoding of ongoing cell assemblies based on extracellular current flows. Differences in the emerging SWR field activity may play an important role in information processing during memory consolidation.

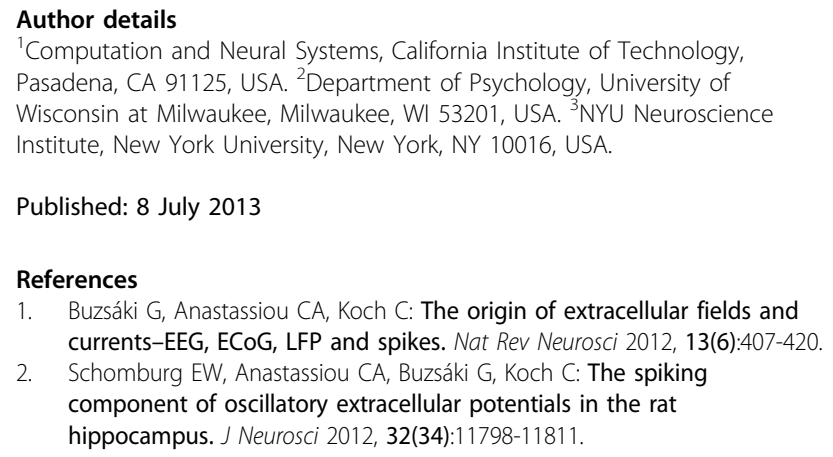

Published: 8 July 2013
References
1. Buzsáki G, Anastassiou CA, Koch C: The origin of extracellular fields and currents-EEG, ECoG, LFP and spikes. Nat Rev Neurosci 2012, 13(6):407-420.
2. Schomburg EW, Anastassiou CA, Buzsáki G, Koch C: The spiking component of oscillatory extracellular potentials in the rat hippocampus. J Neurosci 2012, 32(34):11798-11811. 
3. Taxidis J, Coombes S, Mason R, Owen MR: Modeling sharp wave-ripple complexes through a CA3-CA1 network model with chemical synapses. Hippocampus 2012, 22(5):995-1017.

4. Gold C, Henze DA, Koch C, Buzsáki G: On the origin of the extracellular action potential waveform: a modeling study. J Neurophys 2006, 95(5):3113-3128

5. Diba K, Buzsáki G: Forward and reverse hippocampal place-cell sequences during ripples. Nat Neurosci 2007, 10(10):1241-1242.

doi:10.1186/1471-2202-14-S1-014

Cite this article as: Taxidis et al:: Extracellular field signatures of CA1 spiking cell assemblies during sharp wave-ripple complexes. BMC

Neuroscience 2013 14(Suppl 1):O14.

Submit your next manuscript to BioMed Central and take full advantage of:

- Convenient online submission

- Thorough peer review

- No space constraints or color figure charges

- Immediate publication on acceptance

- Inclusion in PubMed, CAS, Scopus and Google Scholar

- Research which is freely available for redistribution

Submit your manuscript at www.biomedcentral.com/submit 